\title{
With A LiTTLE HELP FROM MY ENEMY: COMPARATIVE ADVERTISING AS A SIGNAL OF QUALITY
}

\author{
FRANCESCA BARIGOZZI \\ Dipartimento di Scienze Economiche \\ P.zza Scaravilli 2 \\ 40126, Bologna, Italy \\ francesca.barigozzi@unibo.it \\ PaOlo G. Garella \\ Dipartimento di Scienze Economiche \\ Aziendali e Statistiche \\ via Conservatorio 7 \\ 20122 Milano, Italy \\ paolo.garella@unimi.it \\ Martin Peitz \\ Department of Economics \\ University of Mannheim \\ 68131 Mannheim, Germany \\ martin.peitz@googlemail.com
}

We extend the theory of advertising as a quality signal using a model where an entrant can choose to advertise by comparing its product to that of an established incumbent. Comparative advertising, comparing quality of one's own product to that of a rival's, empowers the latter to file for court intervention if it believes the comparison to be false or misleading. We show that comparative advertising can be a signal in instances where generic advertising is not viable.

\section{INTRODUCTION}

This paper analyzes comparative advertising as a signal of product quality. Comparative claims differ from generic ones as they open up different strategic opportunities for rivals. Comparative advertising contains both, wasteful advertising expenditure and an implicit or

Two anonymous referees and a coeditor of this journal provided valuable comments and suggestions. An earlier version of this paper was presented at the annual meeting of the European Economic Association, University of Venice, August 2003. The authors gratefully acknowledge the support from University of Crete (contract no. MTKD-CT014288) Marie Curie Transfer of Knowledge-EU's 6th F.P. 
explicit quality claim (such as "my product is better than my rival's one"). This claim can be contested and is ex post verifiable by the court. Hence, the rival firm has the possibility to make the court active by starting a legal action against the advertiser. Comparative advertising thus combines elements of directly and indirectly informative advertising.

Economic theory typically treats directly and indirectly informative advertising separately (for a comprehensive survey see Bagwell, 2007). When it is directly informative, advertising transmits information to consumers either because such information is easily verifiable (as for search attributes of products like price and location) or because false claims are efficiently sanctioned. Obviously, in the latter case laws and legal practice are essential for advertising claims to be truthful and, thus, informative. By contrast, when advertising is informative in an indirect way, it is informative irrespective of content. The last approach is based on the idea that high advertising expenditures work as a device to signal high product quality (e.g., Nelson, 1974; Kihlstrom and Riordan, 1984; Milgrom and Roberts, 1986). The signaling argument, intended to apply to generic advertising, implies that the expenditure and not the content of an ad is what really matters. This paper considers advertising which potentially has information content but where the advertising strategy may also involve wasteful expenditures.

In many countries, the law raises barriers against unfair use of (all types of) advertising. However, a firm using comparative advertising is at a particularly high risk of costly litigation. In particular, advertising firms using a comparative claim risk to be prosecuted by competitors that are explicitly or implicitly named. ${ }^{1}$ Take as an example the 1999 General Motors Corp. ad claiming that the Cadillac Seville STS outperforms BMW 540 in a slalom race. BMW had relevant information and strong incentives to react to the claim, if false.

Costly litigation may be followed by significant damages. Damages include "lost" profits, corrective advertising expenses, and punitive damages. In a number of cases in the U.S. punitive damages have been significant. In 1986, U-Haul International claimed the comparative advertising campaign by Jartran "do-it-yourself" moving company was false and in violation of Lanham Act: the court agreed and awarded $\$ 40$ million in damages, half of which were punitive. ${ }^{2}$

1. See also the discussion in subsections 4.1 and 4.2.

2. Notice that it is generally difficult to prove that consumers are really misled by an ad. This problem was solved by the court ruling that when a marketer spends "substantial funds" in an advertising campaign, the court will presume that consumers were misled if the ad is determined to be false. In another case, in 2000 a federal judge ruled that Papa John's must pay over $\$ 468,000$ in damages to Pizza Hut and desist from using its tag line "Better ingredients. Better pizza." The ruling was in favor of Pizza Hut, as the ingredient comparison was found to be misleading. In fact, the claim cannot 
We consider a duopoly situation in which the incumbent sells a product of known quality, while the entrant's quality is yet unknown to consumers. The entrant and the incumbent sequentially receive an imprecise and private signal on the entrant's quality. The entrant may use dissipative advertising as a signal of quality. A low-quality entrant would like to be perceived to be of high quality. By contrast, a highquality entrant does not want to be confused with a low-quality entrant. The entrant can choose among generic or comparative advertising (or choose not to advertise at all). If advertising is comparative, the entrant claims that its quality is not lower than the incumbent's. Although the choice of comparative advertising empowers the rival with the right to go to court, generic content-free advertising does not. Hence, if the entrant uses comparative instead of generic or no advertising it chooses to give the incumbent the option to go to court. Therefore, consumers can infer that the entrant must think to have a strong case. Although this general statement can easily be understood, our analysis is warranted as far as it provides a detailed analysis of the signaling role of comparative advertising, and it brings to the surface the impact of the incumbent's information about the entrant's quality on equilibrium outcomes. To support comparative advertising as a signal, two features from the literature of directly and indirectly informative advertising are combined: content claims and money burning. Interestingly, for some parameters of the model the use of comparative advertising may not involve any money burning; in this case modeling comparative advertising as directly informative advertising can be seen as an appropriate short cut. In this respect, our analysis reveals which legal environment and information structure leads to such an outcome.

In our model, high quality and low quality lead to the same variable costs. This allows us to exclude pure price signaling and priceadvertising signals with generic advertising as equilibrium outcomes. As we show, comparative advertising can work as a signal of product quality because, due to the court's action, high- and low-quality entrants have different incentives to use this type of advertising. In addition, due to the payment of damages, the incumbent has an incentive to go to court if he believes that his legal action is sufficiently likely to succeed. We distinguish between two types of equilibria: unconditionally contested and conditionally contested comparative advertising equilibria. In the first type of equilibrium, it is optimal for the incumbent not to condition his strategy on his private information about the entrant's quality, such that he brings every comparative advertising claim to court. In the

be scientifically substantiated nor taste tests exist that prove a statistically significant preference for Papa John's product. For details, see Barigozzi and Peitz (2006). 
second type of equilibrium, the incumbent only goes to court if its private information suggests that the entrant is of low quality. The type of equilibrium which prevails, among others things, depends on the informativeness of the signals entrant and incumbent receive and on the monetary transfers imposed by the court.

Our model shows that with efficient courts that are able to obtain rather precise information about the entrant's product quality and are willing to impose damages, comparative advertising should be a widely used marketing instrument. ${ }^{3}$ Relevant sectors are food, retail, and motoring, in which entrant often rely heavily on aggressive marketing strategies.

Comparative advertising has become increasingly popular in recent years. ${ }^{4}$ Perhaps the single most important reason for the more widespread use of comparative advertising is a change in public policy. In particular, in 1979 in the United States the Federal Trade Commission encouraged the use of comparative advertising because direct comparison ads would enable consumers to make more informed purchasing decisions-moreover, comparison ads would ease the consumer's task of evaluating the performance of particular brands against other brands (see the FTC statement, available at http: $\backslash \backslash$ www.ftc.gov). ${ }^{5}$ Our paper provides a formal analysis of this alleged information role of comparative advertising.

Our analysis refers to comparative advertising claims that use the established quality of an incumbent as an anchor. Formally, our model does not distinguish between comparative and noncomparative quality advertising claims. Thus, as long as the incumbent is as likely to succeed

3. In spite of some researchers in marketing being cautious about the general effectiveness of comparative advertising (see, e.g., Shimp, 1990; Pechmann and Ratneshwa, 1991; Jain et al., 1998; Barone and Miniard, 1999), the marketing literature agrees that if a brand has a small market share, or is unfamiliar to buyers, it can enhance the relevance of an ad by naming a leading brand, which is regularly purchased or is familiar to consumers (e.g., Shimp and Dyer, 1978; Muehling et al., 1990; Pechmann and Stewart, 1990; Gnepa, 1993). This belief is shared by practitioners. For example, according to Mitsubishi's marketing manager the company used comparative advertising when entering the European market, "to guide the consumer by making associations with top brand names" (Alison Coleman in Director; London, June 2000).

4. Until the 1970s the use of comparative advertising appears to have been negligible. For the United States in the 1980s, Muehling et al. (1990) report that around $40 \%$ of all advertising was comparative. Pechmann and Stewart (1990) on different data find a percentage as high as $80 \%$. Although the precise definition of comparative advertising is debatable these numbers demonstrate the frequent use of implicit or explicit comparison claims in advertising.

5. In the European Union, the use of comparative advertising was not encouraged (and, in some countries, explicitly banned) and still appears to be less common than in the United States. Practice among member states was markedly different and laws on comparative advertising were harmonized only in April 2000. For a general discussion of comparative advertising from an antitrust perspective, see Barigozzi and Peitz (2006). 
in challenging content claims that are noncomparative in nature, our results apply to content advertising more generally. Then in our model "comparative advertising" can be replaced by "content advertising" more generally. Our argument also extends to content claims that can be contested by third parties such as public authorities and consumer associations (see the discussion section).

The literature on comparative advertising is scarce. Shy (1992, 1995, chap. 11) assumes that comparative advertising is directly informative and focuses on the matching of heterogeneous consumers with differentiated brands. Anderson and Renault (2006b) consider comparative advertising with respect to horizontal characteristics in a market with known quality differences and analyze information disclosure by rival firms. By contrast, Aluf and Shy (2001) postulate that (negative) comparative advertising is persuasive and decreases the willingness to pay for the competitor's product. Our paper differs from these works by taking the view that claims in comparative ads are potentially misleading.

In the literature on indirectly informative advertising, we add to the seminal work by Nelson (1974), Kihlstrom and Riordan (1984), and Milgrom and Roberts (1986), as explained above. ${ }^{6}$ In this literature, the paper that is closest to ours is Matthews and Fertig (1990). ${ }^{7}$

To summarize, our paper lies at the intersection of two strands of literature on advertising. One strand considers directly informative advertising (see, e.g., Anderson and Renault, 2006a, and Meurer and Stahl, 1994). As it was mentioned before, in this literature content claims are always truthful so that the question of the credibility of these claims does not arise. Another strand considers indirectly informative advertising, that is, money burning is perceived by consumers as a signal of product quality. In this literature, no content claims are made. In our setup, comparative advertising contains content claims that are

6. There is somewhat related work that considers actions by the entrant different from advertising that make her profits sensitive to detected quality. These actions include money-back guarantees and warranties (see, e.g., Moorthy and Srinivasan, 1995, and Shieh, 1996). In our paper, the success of the entrant's signaling efforts relies on the possible reaction by her rival, in contrast to this work.

Moreover, the present paper can be seen as complementary to the literature on generic advertising and market entry (Bagwell and Ramey, 1988; Bagwell and Ramey, 1990; Linnemer, 1998). In these papers, the advertising strategy is undertaken by the incumbent to deter entry, whereas in our model it is taken by an entrant to improve its position in the market.

7. In their model, an incumbent and an entrant can use dissipative generic advertising to signal the entrant's quality. Similar to our model, their model allows for a reaction by the incumbent to the entrant's advertising decision. However, their model is markedly different from ours: in particular, the incumbent's reaction is in the form of a counteradvertising campaign and, more importantly, the incumbent's strategy space is not affected by the entrant's advertising decision. 
not necessarily truthful and are supported through publicly observable money burning.

The plan of the paper is as follows. In Section 2, we present the model and find that neither pure price signals nor price-advertising signals with generic advertising are viable in our setup. In Section 3, we characterize the two types of comparative advertising equilibria, unconditionally contested and conditionally contested comparative advertising equilibria. In Section 4, we discuss modifications and extensions of the model.

\section{A DUOPOLY MODEL WITH ASYMMETRIC INFORMATION}

We consider a market where an established firm, the incumbent $I$, sells a product of known high quality $q_{I}=q^{H}$ and a new firm, entrant $E$, has entered with a product of quality $q_{E}$, which may be either high or low, $q_{E} \in\left\{q^{L}, q^{H}\right\}$. In our simple model with two quality levels our argument equally holds if the incumbent is of known low quality. Both firms have some market power, for example, because they offer horizontally differentiated products. Then we may think of products with two characteristics, a horizontal one along which firms necessarily differ and a vertical one which affects all consumers in the same way (for a concrete specification see Barigozzi et al., 2006). The two firms and a population of consumers play a multistage game with a sequence of moves that shall be explained in the following, after some preliminary description of the environment.

Direct information about product quality: The entrant's quality is jointly determined by some random event, which determines her potential quality $\hat{q}_{E} \in\left\{\hat{q}^{L}, \hat{q}^{H}\right\}$, and by her effort $e \in\{0,1\}$. High quality $q^{H}$ results from the combination of a high-quality technology (i.e., high potential quality) and high effort by the entrant, $e=1$. Whenever the entrant uses a low-quality technology or exerts low effort, her quality is low, $q_{E}=q^{L}$. This means that the entrant of high potential quality only distinguishes herself from a firm with low potential quality if she chooses effort $e=1{ }^{8}$ Nature draws from a pool of high- and low-quality technologies. The former is chosen with probability $\alpha_{0}$, the latter with probability $1-\alpha_{0}$. Before deciding whether to exert effort, the entrant receives some noisy private information about her technology. If the entrant has a highquality technology, the entrant receives the signal $s_{E}=s^{H}$. If she has a low-quality technology, the entrant observes the (wrong) signal $s_{E}=s^{H}$ with probability $\lambda_{E}$; and the correct signal $s_{E}=s^{L}$ with probability

8. If we assumed that $\hat{q}^{L}=0$ and $\hat{q}^{H}$ be a strictly positive number, then we could have actual quality to be equal to the product $q_{E}=e \hat{q}_{E}$. 
$\left(1-\lambda_{E}\right)$. We thus have $\operatorname{Prob}\left\{s_{E}=s^{H} \mid \hat{q}^{H}\right\}=1, \operatorname{Prob}\left\{s_{E}=s^{L} \mid \hat{q}^{H}\right\}=0$, $\operatorname{Prob}\left\{s_{E}=s^{H} \mid \hat{q}^{L}\right\}=\lambda_{E}, \operatorname{Prob}\left\{s_{E}=s^{L} \mid \hat{q}^{L}\right\}=1-\lambda_{E}$. Hence, if the entrant observes $s^{H}$ she cannot be sure whether the product is of high potential quality $\hat{q}^{H}$ whereas, if she observes $s^{L}$, she knows that her product is of low quality $\hat{q}^{L}=q^{L} \cdot{ }^{9}$ After observing the signal $s^{H}$ the entrant infers that she has a high-quality technology with probability

$\alpha_{1} \equiv \operatorname{Prob}\left\{q_{E}=\hat{q}^{H} \mid s_{E}=s^{H}\right\}=\frac{\alpha_{0}}{\alpha_{0}+\left(1-\alpha_{0}\right) \lambda_{E}}$.

Consumers and the incumbent do not observe the entrant's signal, nor its effort. Note that irrespective of the signal received, when no other player could upset consumers' beliefs, an entrant would gain if consumers hold the belief that she had received signal $s^{H}$ and exerted effort $e=1$.

We assume that, after price competition has taken place between the two firms, the incumbent uses his own noisy detection technology in order to collect some information about the entrant's true quality (given that the entrant already chose whether to exert effort or not). We assume in particular that: if $q_{E}=q^{H}$, the incumbent observes signal $s_{I}=s^{H}$ with probability 1 ; if $q_{E}=q^{L}$ the incumbent observes signal $s^{H}$ with probability $\lambda_{I}$ and signal $s^{L}$ with probability $1-\lambda_{I}$, that is, $\operatorname{Prob}\left\{s_{I}=s^{H} \mid q^{L}\right\}=\lambda_{I}$ and $\operatorname{Prob}\left\{s_{I}=s^{L} \mid q^{L}\right\}=1-\lambda_{I}$. Hence, if the incumbent observes $s^{L}$ he knows that the entrant is of low quality and that going to court will be successful. We assume that incumbent's and entrant's signal are independent so that the probability that both observe the wrong signal is: $\operatorname{Prob}\left\{s_{I}=s^{H} \wedge s_{E}=s^{H} \mid q^{L}\right\}=\lambda_{I} \lambda_{E}$.

Hence, entrant and incumbent receive signals $s_{j} \in\left\{s^{L}, s^{H}\right\}$, for $j=$ $E, I$. Probability $1-\lambda_{j}$ represents the accuracy of the signal received by firm $j$. It depends on the particular market whether the incumbent or the entrant obtain more precise information. Thus, although we could allow for both cases we shall focus on the case $1-\lambda_{E} \geq 1-\lambda_{I}$. In fact, in the innovation phase, the entrant is likely to obtain more precise information about the merits of her technology because it can use information acquired during development. For this reason, the entrant is likely to be better informed than the incumbent about her potential to produce high quality. However, we reckon that because the incumbent has time to test the product before he decides whether to react to a comparative claim, the case $1-\lambda_{E} \geq 1-\lambda_{I}$ can also be relevant.

As for the incumbent, he will revise his beliefs about the entrant's quality after observing the entrant's advertising strategy and again after

9. It is straightforward to allow for $\operatorname{Prob}\left\{s_{E}=s^{L} \mid \hat{q}^{H}\right\}>0$. In the separating equilibrium with comparative advertising the entrant then wrongly decides not to exert effort if $s_{E}=s^{L}$ but potential quality is high. Our main results are robust to this modification. 
receiving the signal $s_{I}$. Consumers neither observe signals $s_{E}$ and $s_{I}$ nor effort $e$.

Advertising: We follow the literature started by Nelson (1974) and assume that advertising has no direct impact on utility or demand. Its only possible influence is, indirectly, through consumers' perception of quality. The type of advertising and its cost are publicly observable. We assume that advertising is not needed to inform consumers of the marketed products' existence; therefore, if consumers were fully informed about the entrant's quality, the entrant would not advertise at all. Advertising, in our context, can be generic, namely, without any verifiable claim, or comparative, namely, with a verifiable comparison of the type "my product is as good as the incumbent's one." Furthermore, in the discussion section, we argue that our model also applies to content advertising which makes no comparison to rivals' products but, contrary to generic claims, contains content claims that can be challenged in court.

The entrant has three options as to the advertising strategy: (i) no advertising $A=0$; (ii) generic advertising with expenditure $A_{g} \geq A_{0}>0$; (iii) comparative advertising with expenditure $A_{c} \geq A_{0}$. To distinguish no advertising from advertising with minimal expenditure, we assume that there is a lower bound for advertising expenditure, $A_{0}>0$, which is necessary to post an ad. Hence $A=0$ stands for the choice not to advertise, $A=A_{0}$ stands for advertising with no signaling cost. The distinction between (ii) and (iii) matters because generic advertising contains no explicit or implicit comparison claim and no legal actions can be taken against it. On the contrary, comparative advertising contains such a claim (possibly in combination with some money burning). This claim can be falsified and is ex post verifiable by the court.

We will see that no separating equilibria exist where the firm can use generic advertising as part of its signalling strategy. This means that, in our model, generic advertising cannot be indirectly informative. By contrast, if the entrant uses comparative advertising the incumbent has the option to go to court. Legal costs and damages, therefore, attach an additional cost to a false or misleading claim by the entrant and she can signal quality using comparative ads (with or without burned money).

Lawsuit threats: The incumbent's action space depends upon the entrant's strategy choice: in the case of comparative advertising, the incumbent's action space is the set $\{\ell, a\}$, where $\ell$ denotes the decision to dispute the entrant's quality claim and file for a lawsuit, while no action (implicitly accept the quality claim) is denoted as $a$. If the entrant 
does not advertise, or if she uses generic ads, and the incumbent cannot file, its action space is trivially $\{a\}$.

We assume that action $a$ has no cost attached, while the choice of $\ell$, which triggers automatically court intervention, implies legal $\operatorname{costs} c_{I}$ for the incumbent and $c_{E}$ for the entrant. Total legal costs are $c=c_{I}+$ $c_{E}$. The court has the ability to check the entrant's product quality: to avoid further complications we assume that the true quality is perfectly revealed to the court. However, we assume that the court does not have any additional evidence, for example, about the realization of the signal received by the entrant, $s_{E}$. If the court asked evidence to the entrant about the value of $s_{E}$ the entrant would be subject to a moral hazard trap and not be credible. ${ }^{10}$ Therefore, the court cannot judge whether the entrant has acted in good faith or not. If the court finds the entrant's quality to be low, the incumbent obtains a payment from the entrant, $d^{L} \geq 0$. If, however, the court finds the entrant's quality to be high, the incumbent shall (partially) cover the entrant's legal cost. In this case, the incumbent pays $d^{H}$ with $0 \leq d^{H} \leq c_{E}$. No payments are made by the entrant if the court finds the entrant's product to be of high quality. ${ }^{11}$ If each party has to bear its own legal costs and no damages are awarded we have $d^{L}=d^{H}=0$.

The multi-stage game: To simplify the description of the game, suppose at this point that only comparative advertising or no advertising is possible. The game then develops as follows:

Stage 1 . Nature randomly chooses the potential quality, $\hat{q}^{H}$ or $\hat{q}^{L}$. High quality is drawn with probability $\alpha_{0}$, low quality with probability $1-\alpha_{0}$. Nature also chooses a signal for the entrant, $s_{E} \in\left\{s^{L}, s^{H}\right\}$, about the result of this draw.

Stage 2a. The entrant observes $s_{E} \in\left\{s^{L}, s^{H}\right\}$ and then chooses effort $e \in\{0,1\}$ with associated cost $e f$, where $f>0$. Signal and effort choice are not observed neither by the incumbent nor by consumers.

Stage $2 \mathrm{~b}$. The entrant chooses not to advertise $A=0$ or spends $A \geq A_{0}$ on comparative advertising.

Stage 3a. The incumbent observes $A$.

10. If $e$ and $s_{E}$ were verifiable, the court could acquit the entrant if $e=1$ and $s_{E}=s^{H}$ or at least decide not to impose punitive damages. Our general insight about the role of comparative advertising is robust to this modification. The main difference is that the precision of the entrant's signal would become less important.

11. Suppose the court does not want to impose damages in the form of lost profits or punitive damages. Then the special case where $d^{L}=c_{I}$ and $d^{H}=c_{E}$ is equivalent to the situation in which the loosing party has to pay all the legal costs which corresponds to the rule in the United Kingdom. By contrast, in the United States, each party bears its own costs. 
Stage $3 b$. Both firms simultaneously set prices $p_{I}$ and $p_{E}$.

Stage 4. Consumers observe advertising and prices (but nothing else), update their beliefs about the entrants quality, and make their purchasing decision.

Stage 5. The incumbent receives signal $s_{I} \in\left\{s^{H}, s^{L}\right\}$ about the entrant's quality and revises beliefs accordingly. If comparative advertising has been chosen at stage $2 b$, the incumbent decides whether to sue the entrant: $z_{I} \in\{\ell, a\}$, where $z_{I}$ is the incumbent's action.

Stage 6. If $A \geq A_{0}$ and $z_{I}=\ell$, the court becomes active and discovers the entrant's type. Final legal payments are made and firms receive profits.

Equilibrium: We use the solution concept of weak Perfect Bayesian Equilibrium. An equilibrium of the game is defined as a strategy profile and a belief system, such that each player's strategy is sequentially rational, and the incumbent's and consumers' beliefs are updated according to Bayes' rule whenever this is possible. An equilibrium is said to be fully separating when consumers' beliefs assign probability 1 to the true state (which depends the signal received by the entrant and the effort choice) and 0 to the other. In particular, we are interested in separating equilibria where the entrant uses no advertising and exerts no effort if she receives signal $s_{E}=s^{L}$, while she chooses a comparative claim and some expenditure level $A$, and she exerts effort $e=1$ if she receives signal $s^{H}$.

Profit functions: We assume that variable costs are independent of quality. Without loss of generality, we set them equal to zero. In addition, apart from the need to provide effort at $\operatorname{cost} f$, there are no additional fixed costs involved for producing high quality. We denote by $\beta$ the probability assigned by consumers to the event that the entrant's quality is high, namely, to the joint event that $\hat{q}_{E}=\hat{q}^{H}$ and that $e=1$. We denote $\Pi_{E}\left(p_{I}, p_{E}, \beta\right)$ the profits, gross of possible costs to provide effort and to advertise, of an entrant who is perceived by consumers to be of high quality with probability $\beta$, given prices $p_{I}$ and $p_{E}$. The incumbents profits, gross of possible legal costs, depend on prices and on probability $\beta$ and is denoted by $\Pi_{I}\left(p_{I}, p_{E}, \beta\right)$.

The entrant's profits are increasing, while the incumbent ones are decreasing in the probability $\beta$. Thus, the following inequalities hold:

- P.1 $\Pi_{E}\left(p_{I}, p_{E}, \beta\right)>\Pi_{E}\left(p_{I}, p_{E}, \beta^{\prime}\right)$ if $\beta>\beta^{\prime}$

- $\mathrm{P} .2 \Pi_{I}\left(p_{I}, p_{E}, \beta\right)<\Pi_{I}\left(p_{I}, p_{E}, \beta^{\prime}\right)$ if $\beta>\beta^{\prime}$. 
Properties (P.1) and (P.2) are standard properties of many oligopoly models where products have some degree of both, horizontal and vertical differentiation. ${ }^{12}$

\section{Comparative advertising as a Signal}

The entrant can choose $e=1$ or $e=0$. Obviously, because the first choice is costly, it makes no sense when $s_{E}=s_{L}$. Therefore, the entrant in our model is interested in signaling that she has chosen $e=1$ and $s_{E}=s^{H}$ . This is the sense in which we use the term "quality signaling" here: it implies separating at the same time from an entrant who receives signal $s_{L}$ and from an entrant who chooses $e=0$. Because $s_{E}=s^{H}$ does not guarantee that the potential quality be $\hat{q}=\hat{q}^{H}$, true quality will indeed remain a random variable on which consumers form expectations even at a separating equilibrium (the equilibrium level of $\beta$ will be always less than 1, as it shall be shown below).

Before addressing the signaling property of comparative advertising we make some observations. First, consumer beliefs are independent of $p_{I}$ because the incumbent does not possess any private information at the price setting stage. Second, to consider generic advertising in our setup, we simply eliminate the possibility for the incumbent to take legal actions in the multi-stage game. Third, in our model the entrant can signal her quality neither with price alone nor with price and generic advertising. This is essentially due to the fact that variable costs are independent of quality and that, at the pricing stage, the incumbent does not have any information about the entrant's quality.

Even though the entrant can signal her quality choice neither with price alone nor with price and generic advertising, she is able to signal quality using comparative advertising. In other words, where price and generic advertising fail as a signal of quality, comparative advertising is able to transmit information to consumers (and to the incumbent): comparative advertising has a higher signaling power than price and generic advertising together. The rest of this section makes this claim precise.

We use the term advertising for comparative advertising because this can be the only viable form of advertising. Note that at a separating equilibrium the incumbent infers the signal that was received by the entrant $s_{E}$ and the entrant's associated effort choice from the entrant's advertising decision. He plays his best response to the price set by the entrant. If $s_{E}=s^{L}$ both firms set mutual best responses $p_{I}^{*}\left(s^{L}\right)$ and $p_{E}^{*}\left(s^{L}\right)$, respectively, and the corresponding net profits are denoted by

12. Several examples are presented and discussed in Garella and Peitz (2000). 
$\pi_{I}^{*}(0)=\Pi_{I}^{*}(0)$ and $\pi_{E}^{*}(0)=\Pi_{E}^{*}(0)$, where prices are replaced by their equilibrium values given $\beta=0$. If $s_{E}=s^{H}$, the entrant may not be able to set its "full information" price (that is the price that would prevail if all parties had learnt $s_{E}=s^{H}$ ) because consumers may have beliefs that assign a low probability to $q_{E}=q^{H}$ at this price. The entrant may therefore want to distort its price and use price together with advertising as a signal of quality. A deviation from the full information prices then would obviously lead to profits that are different from the full information ones. To avoid the entrant with $s_{E}=s^{L}$ or $e=0$ to mimic the behavior of the entrant with $s_{E}=s^{H}$ and $e=1$ the advertising expenditure (and, possibly, the deviation from the full information price) has to be chosen sufficiently large to assure that the entrant's separating constraint is satisfied.

DEFINITION 1: We distinguish two types of separating equilibria. In both these equilibria the entrant chooses $e=0$ and no advertising, $A=0$, if she observes $s_{E}=s^{L}$ :

1. Unconditionally contested comparative advertising equilibria (UCA). The entrant chooses $e=1$ and comparative advertising with $A \geq A_{0}$, if she observes $s_{E}=s^{H}$; independent of the realization of $s_{I}$ the incumbent files for a lawsuit whenever the entrant has advertised.

2. Conditionally contested comparative advertising equilibria (CCA). The entrant chooses $e=1$ and comparative advertising with $A \geq A_{0}$, if she observes $s_{E}=s^{H}$; the incumbent files against advertising only if he observes $s_{I}=s^{L}$.

In both types of comparative advertising equilibria the incumbent claims damages if comparative advertising was used in state $s_{I}=s^{L}$. What distinguishes these two types of equilibria is the incumbent reaction if he observes $s_{I}=s^{H}$. At a CCA, along the equilibrium path, the incumbent reacts to advertising only if the signal he receives diverges from the one that the entrant has observed. At a UCA, the incumbent always contests comparative advertising claims. Clearly, if the incumbent's signal $s_{I}$ is uninformative a CCA cannot exist. We analyze the role of the incumbent's information in more detail in Section 3.3.

At a separating equilibrium, if the entrant undertakes an advertising campaign, consumers infer that the entrant received the signal $s_{E}=s^{H}$ and that she exerted effort $e=1$. They update their beliefs accordingly, that is, they believe that the product is of high quality with probability $\alpha_{1}$ as given by (1). ${ }^{13}$

13. Note that we restrict attention to pure strategies. If we allow for mixing additional equilibria may exist. In such a case, the signaling power of comparative advertising would 
For the incumbent, the decision whether to file against the entrant is taken after the signal $s_{I}$ has been observed. Let us consider the incumbent's incentive to react to a comparative ad when he observes the signal $s_{I}=s^{L}$, that is when he learns that the rival's quality is low. Suppose that $d^{L}>c_{I}$. By reacting to a misleading ad, the incumbent obtains $\pi_{I}\left(p_{I}, p_{E}, \alpha_{1}\right)=\Pi_{I}\left(p_{I}, p_{E}, \alpha_{1}\right)-c_{I}+d^{L}$, whereas he obtains only $\Pi_{I}\left(p_{I}, p_{E}, \alpha_{1}\right)$ if he does not react. Hence the action $a$ is strictly dominated by $\ell$. We can state the following lemma.

Lemma 1: Suppose that $d^{L}>c_{I}$. Then in any separating equilibrium of the game, the incumbent's strategy in response to the use of comparative advertising is to file a lawsuit $\ell$ if he observes $s_{I}=s^{L}$.

Note that the signaling mechanism can work as long as the incumbent can at least recover his legal costs.

Let us consider now the incumbent's incentive to react to a comparative ad when he observes the signal $s_{I}=s^{H}$. When $s_{I}=s^{H}$ the incumbent assigns revised probability $\alpha_{2}$ to the event that the entrant be of high quality and that going to court will not be successful,

$\alpha_{2}=\operatorname{Pr}\left\{q_{E}=q^{H} \mid s_{E}=s^{H} \wedge s_{I}=s^{H}\right\}=\frac{\alpha_{0}}{\alpha_{0}+\left(1-\alpha_{0}\right) \lambda_{I} \lambda_{E}}$.

Accordingly, the incumbent's expected profits from filing are equal to $\Pi_{I}\left(p_{I}, p_{E}, \alpha_{1}\right)+\left(1-\alpha_{2}\right) d^{L}-\alpha_{2} d^{H}-c_{I}$. Although profits from not filing are simply $\Pi_{I}\left(p_{I}, p_{E}, \alpha_{1}\right)$. Hence the incumbent files in state $s^{H}$ if and only if

$\alpha_{2} \leq \hat{\alpha} \equiv\left(d^{L}-c_{I}\right) /\left(d^{L}+d^{H}\right)$,

that is, the incumbent always chooses $\ell$ when the probability $\alpha_{2}$ that the entrant is a high-quality producer is low enough. This is more likely to be satisfied if the precision of the signals $1-\lambda_{I}$, and $1-\lambda_{E}$ are low. If $\alpha_{2}>\hat{\alpha}$, the incumbent does not file when $s_{I}=s^{H}$ and thus a UCA cannot be supported as an equilibrium.

Because we are interested in signaling power of comparative advertising, we will focus on separating equilibria in which the entrant does not distort her price for signaling purposes. This will allow us to characterize separating equilibria with comparative advertising in the absence of price distortions. Because variable costs are zero, we know that one of the separating equilibria, provided they exist, has the property that incumbent and entrant set prices according to their full information best responses, that is, the entrant with $s_{E}=s^{H}$ does not

be lower because consumers' up-dated beliefs that the entrant's quality is high will be lower than $\alpha_{1}$. 
need to distort its price to convince consumers that she received signal $s_{E}=s^{H}$. This equilibrium is robust to forward induction arguments captured by the intuitive criterion by Cho and Kreps (1987) or stability by Kohlberg and Mertens (1986) because price distortions are equally attractive for entrants with $s_{E}=s^{L}$ and $s_{E}=s^{H} .{ }^{14}$ In particular, we can hold the beliefs constant in the entrant's price. The entrant's gross profits that follow from the solution of the first-order conditions, in the system of the Nash best replies equations, with nondistorted prices, is denoted by $\Pi_{E}^{*}\left(\alpha_{1}\right)$ for $s_{E}=s^{H}$. Again, net profits are denoted by $\pi_{E}^{*}\left(\alpha_{1}\right)$.

\section{1 THE CASE $\alpha_{2} \leq \hat{\alpha}$ : UnCONDITIONALLY CONTESTED COMPARATIVE ADVERTISING EQUILIBRIA (UCA)}

Recall that at a UCA equilibrium the incumbent always reacts to a comparative ad, on and off the equilibrium path. The entrant's separating constraint when she observes $s_{E}=s^{L}$ is

$\pi_{E}^{*}(0) \geq \Pi_{E}^{*}\left(\alpha_{1}\right)-A-d^{L}-c_{E}$

while (including the cost of effort) the separating constraint ensuring that an entrant has observed $s_{E}=s^{H}$ and has played $e=1$ is

$\Pi_{E}^{*}\left(\alpha_{1}\right)-A-\left(1-\alpha_{1}\right) d^{L}+\alpha_{1} d^{H}-c_{E}-f \geq \pi_{E}^{*}(0)$.

Note the difference with respect to the case in which the court cannot be active. Here, the fact that the court gathers information about true quality and enforces side payments between the parties (depending on this information), can make comparative advertising a credible signal. The court becomes active because the incumbent expects to benefit in spite of paying legal costs.

Proposition 1: Suppose inequality (3) is satisfied. An unconditionally contested comparative advertising equilibrium entails a level of expenditure A such that

$$
\begin{array}{r}
\Pi_{E}^{*}\left(\alpha_{1}\right)-\pi_{E}^{*}(0)-d^{L}-c_{E} \leq A \leq \Pi_{E}^{*}\left(\alpha_{1}\right) \\
-\pi_{E}^{*}(0)-\left(1-\alpha_{1}\right) d^{L}+\alpha_{1} d^{H}-c_{E}-f .
\end{array}
$$

UCA equilibria exist if $\alpha_{1}\left(d^{L}+d^{H}\right) \geq f$.

14. In our model, a price distortion is akin to money burning for the entrant and there is a continuum of separating equilibria that are payoff-equivalent for the entrant. This is different from other models with price and advertising signals of quality such as Milgrom and Roberts (1986), in which there is a role for price distortions (possibly together with advertising expenditure) to signal product quality. In that model, using equilibrium selection arguments such as the intuitive criterion by Cho and Kreps (1987) or strategic stability by Kohlberg and Mertens (1986) the firm will not set its full information price if it is of high quality. 
As a special case, if the damages $d^{L}$ are large enough, the entrant pays just the minimal amount $A_{0}$ and does not need to burn any additional money to credibly transmit information to consumers. In other words, a claim that the state is $s^{H}$ and effort is $e=1$ can be supported without a proper signaling cost if the lower bound in (6) is less than $A_{0}$. In this case, the entrant does not incur any dissipative advertising costs to make the signal credible. It is as if the entrant was telling consumers: Because my rival can inflict a loss upon me if I lie, you must to a large extent believe my words that my product is of comparable quality. Interestingly, in such a situation one can see a model with directly informative comparative advertising as a short cut of our model because the advertising firm does not incur any signaling cost. Note also that, in a situation in which comparative advertising transmits information without a cost so that $A_{0}=0$, the entrant prefers not to use price as a signal of product quality because a price distortion is costly whereas advertising is not.

In the case where $A>A_{0}$ the entrant uses dissipative advertising expenditure together with the comparative claim to signal quality to consumers. The higher the damages and legal costs the entrant has to pay, the more effective is comparative advertising in transmitting information in the sense that less money is burnt (as it is apparent by inspection of the lower bound in (6) above).

The entrant's expected profit using the minimum levels of advertising in the case of unconditionally contested comparative ads are computed as follows. Before receiving any signal, the entrant expects with probability $\alpha_{0}$ to be of type $q^{H}$, in this case to observe $s_{E}=s^{H}$, to pay $f+A$, and to be contested. Profits then are $\Pi_{E}\left(\alpha_{1}\right)-f-A+d^{H}-c_{E}$. Similarly, with probability $\left(1-\alpha_{0}\right)$ she expects to be of quality $q^{L}$. In this case, with probability $\left(1-\lambda_{E}\right)$ she observes signal $s_{E}=s^{L}$, does not advertise and obtains profits $\pi_{E}^{*}(0)$. However, with probability $\lambda_{E}$ she observes signal $s_{E}=s^{H}$, pays $f+A$, is contested, and will pay damages $d^{L}+c_{E}$. Profits then are $\Pi_{E}\left(\alpha_{1}\right)-f-A-d^{L}-c_{E}$. The entrant's expected equilibrium profit before receiving the signal is

$$
\begin{aligned}
E\left(\Pi_{E}\right)= & \alpha_{0}\left(\Pi_{E}^{*}\left(\alpha_{1}\right)-f-A+d^{H}-c_{E}\right) \\
& +\left(1-\alpha_{0}\right)\left[\left(1-\lambda_{E}\right) \pi_{E}^{*}(0)+\lambda_{E}\left(\Pi_{E}^{*}\left(\alpha_{1}\right)-f-A-d^{L}-c_{E}\right)\right] .
\end{aligned}
$$

By substituting $A$ with its minimum level, namely, $A_{\min }=\Pi_{E}^{*}\left(\alpha_{1}\right)-$ $\pi_{E}^{*}(0)-d^{L}-c_{E}$, this reduces to

$$
E\left(\Pi_{E}\right)=\pi_{E}^{*}(0)-\left(\alpha_{0}+\left(1-\alpha_{0}\right) \lambda_{E}\right) f+\alpha_{0}\left(d^{H}+d^{L}\right),
$$

provided that $A_{\min } \geq A_{0}$. 


\subsection{ThE CASE $\alpha_{2} \geq \hat{\alpha}$ : CONDITIONALly CONTESTED COMPARATIVE ADVERTISING EQUILIBRIA (CCA)}

Recall that a CCA has the property that the entrant only uses comparative advertising if her signal is $s_{E}=s^{H}$ (as in a UCA) and the incumbent only goes to court as a response to comparative advertising if his signal is $s_{I}=s^{L}$. Because in our model the court does not make mistake and a signal $s_{I}=s^{L}$ is fully revealing, a CCA has the property that along the equilibrium path the entrant is always found guilty.

The entrant's revised probability that the incumbent gets signal $s_{I}=s^{H}$ depends upon the signal $s_{E}$ that she has observed herself. If the entrant has received signal $s_{E}=s^{H}$ she knows that the incumbent can only receive signal $s_{I}=s^{L}$ if the quality is $q_{E}=q^{L}$. Hence, $\operatorname{Prob}\left(s_{I}=\right.$ $\left.s^{L} \mid s_{E}=s^{H}\right)=\operatorname{Prob}\left(s_{I}=s^{L} \mid q_{E}=q^{L}\right) \operatorname{Prob}\left(q_{E}=q^{L} \mid s_{E}=s^{H}\right)=(1-$ $\left.\lambda_{I}\right)\left(1-\alpha_{1}\right)$. This implies that $\operatorname{Prob}\left(s_{I}=s^{H} \mid s_{E}=s^{H}\right)=\alpha_{1}+\left(1-\alpha_{1}\right) \lambda_{I}$. If the entrant has observed $s_{E}=s^{L}$ she knows that the quality is low (with probability 1). Thus $\operatorname{Prob}\left(s_{I}=s^{H} \mid s_{E}=s^{L}\right)=\lambda_{I}$ and $\operatorname{Prob}\left(s_{I}=\right.$ $\left.s^{L} \mid s_{E}=s^{L}\right)=1-\lambda_{I}$.

Suppose the entrant has observed $s_{E}=s^{L}$. If this entrant mimics the entrant who received signal $s^{H}$, she knows that with probability $\operatorname{Prob}\left(s_{I}=s^{L} \mid s_{E}=s^{L}\right)=1-\lambda_{I}$ the incumbent will go to court, in which case she will always loose. The expected profit of a cheating entrant is therefore $\Pi_{E}^{*}\left(\alpha_{1}\right)-A-\left(1-\lambda_{I}\right)\left(d^{L}+c_{E}\right)$ and the separating constraint for an entrant receiving signal $s_{L}$ is

$\pi_{E}^{*}(0) \geq \Pi_{E}^{*}\left(\alpha_{1}\right)-A-\left(1-\lambda_{I}\right)\left(d^{L}+c_{E}\right)$.

Because $\left(1-\lambda_{I}\right)\left(1-\alpha_{1}\right)$ is the probability that the incumbent observes signal $s_{I}=s^{L}$ given signal $s_{E}=s^{H}$, the separating condition for an entrant who has received signal $s^{H}$ is

$\Pi_{E}^{*}\left(\alpha_{1}\right)-A-f-\left(1-\alpha_{1}\right)\left(1-\lambda_{I}\right)\left(d^{L}+c_{E}\right) \geq \pi_{E}^{*}(0)$.

Rewriting these two inequalities we obtain the following result:

Proposition 2: Suppose inequality (3) is not satisfied. A conditionally contested comparative advertising (CCA) equilibrium entails a level of expenditure A such that

$$
\begin{aligned}
& \Pi_{E}^{*}\left(\alpha_{1}\right)-\pi_{E}^{*}(0)-\left(1-\lambda_{I}\right)\left(d^{L}+c_{E}\right) \leq A \leq \Pi_{E}^{*}\left(\alpha_{1}\right)-\pi_{E}^{*}(0) \\
& \quad-f-\left(1-\alpha_{1}\right)\left(1-\lambda_{I}\right)\left(d^{L}+c_{E}\right)
\end{aligned}
$$

CCA equilibria exist if $\alpha_{1}\left(1-\lambda_{I}\right)\left(d^{L}+c_{E}\right) \geq f$. 
As it is apparent from inspection of (10) at a conditionally contested separating equilibrium, the minimum amount of advertising necessary to signal quality is decreasing in the precision of the signal observed by the incumbent. Recalling the expression for $\alpha_{1}$ and $\alpha_{2}$ as given, respectively, in (1) and (2), we observe that conditionally contested comparative equilibria tend to be compatible with high precision both of the entrant's and the incumbent's signal.

The expected profit to an entrant using the minimum levels of advertising in the case of conditionally contested comparative ads are computed as follows. Before receiving any signal, the entrant expects with probability $\alpha_{0}$ to be of type $q^{H}$, to observe $s_{E}=s^{H}$, and to pay $f+A$ without being contested, getting profits $\Pi_{E}^{*}\left(\alpha_{1}\right)-f-A$. Similarly, with probability $\left(1-\alpha_{0}\right)$ she expects to be of quality $q^{L}$. In this case, with probability $\left(1-\lambda_{E}\right)$ she observes signal $s_{E}=s^{L}$, does not advertise, and gets profits $\pi_{E}^{*}(0)$. However, with probability $\lambda_{E}$ she observes signal $s_{E}=$ $s^{H}$, pays $f+A$, and is contested with probability $\left(1-\lambda_{I}\right)$, in which case she will pay damages $d^{L}+c_{E}$ and get profits $\Pi_{E}^{*}\left(\alpha_{1}\right)-f-A-d^{L}-c_{E}$. Then, the expected profit to an entrant before receiving the signal is

$$
\begin{aligned}
E\left(\Pi_{E}\right)= & \alpha_{0}\left(\Pi_{E}^{*}\left(\alpha_{1}\right)-f-A\right)+\left(1-\alpha_{0}\right)\left(1-\lambda_{E}\right) \pi_{E}^{*}(0) \\
& +\left(1-\alpha_{0}\right) \lambda_{E}\left[\left(1-\lambda_{I}\right)\left(\Pi_{E}^{*}\left(\alpha_{1}\right)-f-A-d^{L}-c_{E}\right)\right. \\
& \left.\left.+\lambda_{I}\left(\Pi_{E}^{*}\left(\alpha_{1}\right)-f-A\right)\right)\right]
\end{aligned}
$$

for $\alpha_{2} \geq \hat{\alpha}$. By substituting $A$ with its minimum level, namely, $A_{\min }=$ $\Pi_{E}^{*}\left(\alpha_{1}\right)-\pi_{E}^{*}(0)-\left(1-\lambda_{I}\right)\left(d^{L}+c_{E}\right)$, this reduces to

$E\left(\Pi_{E}\right)=\pi_{E}^{*}(0)-\left(\alpha_{0}+\left(1-\alpha_{0}\right) \lambda_{E}\right) f+\alpha_{0}\left(1-\lambda_{I}\right)\left(d^{L}+c_{E}\right)$,

which is increasing in $\left(1-\lambda_{I}\right)$. Hence it follows:

COROLlary 1: (a) In the case of conditionally contested comparative advertising equilibria, the minimum amount of advertising necessary to signal quality is decreasing and the expected profit of an entrant is increasing in the precision of the signal received by the incumbent. (b) The minimum amount of advertising necessary to signal quality is decreasing and the expected profit of an entrant is increasing in the level of damages $d^{L}$.

One may speculate that the entrant would design her product so as to make quality claims easily testable by the incumbent, namely, in such a way as to increase the value of $1-\lambda_{I}$.

\subsection{THE ROLE OF THE INCUMBENT'S INFORMATION}

In this subsection, we investigate the role of the incumbent's information in more detail. Once the incumbent has been given the ability to react to 
comparative advertising, does it matter for him to receive some private information about the entrant's quality?

As a start, consider the case where the entrant receives a signal but the incumbent receives no signal, which is equivalent to the case where $\lambda_{E}<1$, while $\lambda_{I}=1$. When $\lambda_{I}=1$ one also has $\alpha_{2}=\alpha_{1}$. This implies that if he received no signal, the incumbent contests comparative advertising claims if and only if $\alpha_{1} \leq \hat{\alpha}$, where $\hat{\alpha}$ is defined as in (3). If $\alpha_{1}>\hat{\alpha}$, therefore, the incumbent would never react to ads and there would exist no equilibria with comparative advertising as a signal. In equilibrium $e=0$ and the entrant's equilibrium profit is always $\pi_{E}^{*}(0)$. Let us compare the case $\lambda_{I}=1$ with the case where $0<\lambda_{I}<1$. Here, the information of the incumbent is valuable for the entrant because it may make comparative advertising viable as a signal in which case the entrant chooses $e=1$ when $s_{E}=s^{H}$. In particular, for some parameter constellations there exist conditionally contested comparative advertising equilibria. Hence, the incumbent reacts if he observes $s_{I}=s^{L}$. The expected profit to the entrant before the game starts is given by (11), which is larger than $\pi_{E}^{*}(0)$.

If $\alpha_{1}<\hat{\alpha}$ and $\lambda_{I}$ locally decreases from 1 , then one still has $\alpha_{2}<\hat{\alpha}$. In this case, the behavior of the incumbent leads to unconditionally contested comparative advertising equilibria irrespective of wether $\lambda_{I}=1$ or $\lambda_{I}<1$, so that in this case there is no difference between giving information to the incumbent or not. If $\lambda_{I}$ is reduced by so much as to have $\alpha_{2}>\hat{\alpha}$, giving information to the incumbent makes him change behavior and be more prudent by reacting only if he observes $s_{I}=s^{L}$; this leads to a CCE instead of a UCE. The entrant's expected profit before the game starts is then as in (11) instead of the expected profit under a UCE given in (7). This difference is always negative.

Hence, there is a case where the information given to the incumbent (here measured by the amount $1-\lambda_{I}$ ) is crucial for obtaining separation, namely, the case where $\alpha_{1}>\hat{\alpha}$. In that case, the expected profits of the entrant are also raised. If by contrast $\alpha_{1}<\hat{\alpha}$ the separating equilibrium either does not change or changes from UCE to CCE and expected profits to the entrant either do not change or decrease.

\section{Discussion}

\subsection{COMPARATIVE VERSUS NONCOMPARATIVE CONTENT ADVERTISING}

We have decided to refer to comparative advertising for two reasons. First, consumers often lack a clear understanding of absolute content statements and it is much easier for the consumer to grasp simple 
messages such as "my product is as good as," rather than interpret a more complex statement about the quality of a product. A good example is nutrition information. Here, advertisers rather state that their products contain a certain percentage more or less than the reference product. Put differently, many product features in isolation (i.e., in the absence to a comparison to a reference product) are not understood by consumers and therefore are an ineffective means of communication. If this is the case, content claims are comparative in nature.

Second, there are instances in which the use of comparative advertising makes the advertiser more vulnerable to lawsuit threats. This in turn makes comparative a more viable signal. This can be exemplified by what the U.S. law defines as "puffery." An ad can be considered puffery as long as "the customer believes the commercial statement is so vague, ridiculous or opinionated that it could not possibly be taken serious" (for a clear explanation see Jim Edwards in Brandweek, New York, May 2001). Puffery is accepted in noncomparative advertising but it becomes illegal whenever it tags a competitor, exactly as in the case of Papa John's ad “Better ingredients better pizza." For details, see Barigozzi and Peitz (2006).

\subsection{Fraudulent Advertising and Public Agencies}

As mentioned in the introduction, our model can be interpreted as a model about advertising with content claims that can be challenged by third parties. If the content claim turns out to be false the entrant is sanctioned by the court. The reaction of the incumbent to comparison ads is one mechanism to have such a pecuniary penalty be imposed. Other different mechanisms for content advertising may involve the intervention of public agencies, like the FTC and the DOJ in the United States and national competition authorities in Europe. Consumer associations also may act on behalf of consumers. In all these cases, a content claim makes a firm vulnerable to lawsuits. This has been remarked by practitioners. For instance, R. Freeman and E. Nemiroff from Collier Shannon Scott, a law firm, note that "comparative advertising can be a very effective marketing tool, but with it comes the risk of challenges by competitors, state attorneys general, and even the FTC. [...] Accordingly, before embarking on a comparative advertising campaign, ask if a skeptical judge would find your substantiation to be adequate. Unless spending large amounts of money and company time on legal challenges is part of your strategic plan, make sure the answer to that question is 'Yes'." (in: We're Number 1: A Guide to Comparative Advertising, March 30, 2001). 
To use our model to understand the difference between content advertising and generic advertising, player $I$ represents the institution which acts as a watchdog. One then has to define the payoff function of this player. If the player is a public authority, its objective function may be welfare measured as unweighted total surplus or consumer surplus (or any convex combination of the two). In a model where the third party is a consumer association, the payoff may be given by consumer surplus. What matters for the mechanism to work is that the entrant's advertising strategy contains some verifiable content claims about quality. Then, the level of advertising expenditure can work as a signal, as in our model.

What is special to comparative advertising in our model, therefore, is not so much the fact that the entrant who misleads risks a penalty (and that consumers use this information to evaluate the entrant's incentives to misrepresent). Rather, what is special is that the mechanism triggering the penalty is enacted by a rival firm. This rival firm would gain by committing not to challenge any quality claims made by the entrant. It is the lack of commitment power that makes comparative advertising viable as a signal. The commitment issue does not arise in the case of other third parties.

To the extent that rival firms have better access to private information about the entrant's product quality, our signaling mechanism may be socially superior to one that relies on the intervention of a public authority. However, because the incumbent's incentives are guided by his own profits, public intervention may be needed to complement for the incumbent's role as a watchdog. To summarize, neither public authorities nor rival firms are a complete safeguard against firms making false content claims, ${ }^{15}$ but the monitoring by both of them can improve the informativeness of content claims and reduce the amount of wasteful advertising.

\subsection{ROLE OF THE COURTS}

In our formal analysis, we assumed that courts find unambiguous evidence and do not make mistakes. If we include the possibility of courts making erroneous decisions it becomes more difficult to use comparative advertising as a signal of product quality. Hence, although our results are robust to small errors by the courts, a well-functioning

15. Witness the recent uproar following the "Ribena" case, where the producer of a largely advertised fruit juice was discovered to have misled consumers for decades not by authorities but by two schoolgirls in New Zealand, while they were making homework experiments for their chemistry class (see, e.g., Jeevan Vasagar, "Schoolgirls rumble Ribena vitamin claims," in The Guardian, March 27, 2007). 
court system is critical for the mechanism to work. We would therefore expect that comparative advertising claims are meaningful only in those countries in which a court properly intervenes when the advertising party is accused of making false claims.

Although literal falsity is easy to define, the ruling of the courts will interact with how market participants (and, in particular consumers) interpret claims of superiority. For instance, general claims of superiority may be ignored by consumers if they make the experience that courts do not punish such behavior but may be taken to contain valuable information in an environment in which courts punish unfounded superiority claims. Also, particular exaggerated claims about relative merits of a particular product may be seen as marketing hype in some countries (and thus in equilibrium ignored by consumers) whereas they may be taken literally in others. For different attitudes with respect to such claims in the United States, the United Kingdom, and continental Europe see Barigozzi and Peitz (2006).

A feature of our simple model, in which firms interacted only once, was that the legal process only started after the product market interaction had taken place. A more general view would be that court's decisions, if taken rapidly, still affect market outcomes. To the extent that the court's action affects consumer beliefs, the incumbent is interested in revealing to consumers that the rival is of low quality. Then it can be shown that even in the absence of payment of damages comparative advertising can be a signaling mechanism (see Barigozzi et al., 2006). In particular, this holds for the polar case, in which the product market opens only after the court's verdict. In this case, an important measure by the court is to force the entrant to pay for corrective advertising so that consumers are correctly informed.

\section{CONCLUSION}

We have shown in this paper that comparative advertising has a different signaling potential than generic advertising. In particular, comparison ads may trigger a reaction by the firm that is the target of the comparison. The strategy space of the incumbent is a function of the entrant's choice about the type of advertising. This may be especially useful for firms wishing to enter into a market in which an incumbent with a renowned brand already operates.

To summarize, the entrant uses comparative advertising to give the incumbent the option to appeal to court. Therefore, consumers can infer that the entrant must think to have a strong case. This logic appears to be consistent with the practitioners' point of view on the use of comparative 
advertising: on the web site of the advertising agency Kaye\&Company (http: \\www.kayeco.com, consulted May 2001) the use of comparative advertising is encouraged because it increases credibility for the advertised product: "Side-by-side or 'A-B' comparisons can provide prospective customers with compelling reasons to buy from you. They can also help build credibility for your product. Subconsciously, the prospective customer says: -Who would risk making a direct comparison if they didn't have something truly superior?-."

The main policy conclusions of the paper are the following. First, in an oligopoly situation, when firms have private information, this information can be revealed to consumers through the use of advertising. If comparison advertising is banned, a channel is shut that allowed information possessed by rivals of advertising firms to play a role. Only the information possessed by the advertising firm can, if at all, be revealed through generic ads, and likely at a higher cost (in our model such a signal is not viable). Note that other forms of content advertising may substitute for comparative advertising. Thus the use of comparative advertising (or other forms of content advertising) can increase the incentive of entrants to provide effort. In effect, they can lower entry costs that are due to asymmetric information and therefore facilitate entry. In this sense, the FTC's view that promoting comparative advertising would promote competition is validated by our results.

Second, it is useful to have a judicial practice that clearly defines what are contestable claims (e.g., verifiable content) so that incumbents can use the law properly in order to react to comparison claims and the courts make few mistakes. If incumbents feel secure that a false or misleading claim is appropriately sanctioned, they will indeed go to court. However, judicial practice should depend on the way in which consumers interpret content claims in comparative advertising. In countries where consumers are not used to an unprotected environment and to aggressive marketing, they may view informal and vague comparison claims, that are not contestable by rivals, as genuinely comparative claims. Then, an active role by courts and antitrust authorities may be required. This may explain the more hostile attitude toward the use of comparative advertising claims in continental Europe compared to, for example, the United Kingdom and the United States (see Barigozzi and Peitz, 2006).

Third, as the model shows, a sufficiently high level of damage payment is necessary to support the signaling mechanism. If, on the contrary, a large share of consumers were to make their purchasing decision after observing the court decision (and the court precision is high), damage payments may not be needed. Hence, the level of damage payment should critically depend on the extent to which the incumbent 
has been hurt by false or misleading claims. If damages are too high, an incumbent may excessively use the court system and the entrant may not venture into comparison ads that would be contested. This would destroy the information transmission channel provided by comparative advertising.

\section{REFERENCES}

Aluf, Y. and O. Shy, 2001, "Comparison-Advertising and Competition," Mimeo, University of Haifa, Israel.

Anderson, S.P. and R. Renault, 2006a, "Advertising Content," American Economic Review, 96, 93-113.

— and - 2006b, "Comparative Advertising," Mimeo, University of Virginia.

Bagwell, K., 2007, “The Economic Analysis of Advertising," M. Armstrong and R. Porter, eds. The Handbook of Industrial Organization, Vol. 3, Amsterdam: North Holland.

— and G. Ramey, 1988, "Advertising and Limit Pricing," RAND Journal of Economics, $19,59-71$.

— and - 1990, "Advertising and Pricing to Deter or Accommodate Entry When Demand is Unknown," International Journal of Industrial Organization, 8, 93-113.

Barigozzi, F., P. Garella, and M. Peitz, 2006, "With a Little Help from My Enemy: Comparative Advertising as a Signal of Quality," University of Bologna discussion paper no. 441. Available at www.ssrn.com.

- and M. Peitz, 2006, "Comparative Advertising and Competition Policy," in J.P. Choi, ed., Recent Trends in Antitrust: Theory and Evidence, Cambridge, MA: The MIT Press, 215-263.

Barone, M.J. and P.W. Miniard, 1999, "How and When Factual Ad Claims Mislead Consumers: Examining the Deceptive Consequences of Copy X Copy Interactions for Partial Comparative Advertisements," Journal of Marketing Research, 36, 58-74.

Cho, I.K. and D.M. Kreps, 1987, "Signaling Games and Stable Equilibria," Quarterly Journal of Economics, 102, 179-221.

Garella, P.G. and M. Peitz, 2000, "Intermediation Can Replace Certification," Journal of Economics and Management Strategy, 9, 1-24.

Gnepa, T., 1993, “Observations: Comparative Advertising in Magazines: Nature, Frequency and a Test of the Underdog Hypothesis," Journal of Advertising Research, 70-75.

Linnemer, L., 1998, “Entry Deterrence, Product Quality: Price and Advertising as Signals," Journal of Economics and Management Strategy, 7, 615-645.

Jain, S.P., B. Buchanan, and D. Maheswaran, 1998, “Comparative Versus Noncomparative Messages: the Moderating Impact of Pre-purchase Attribute Verifiability," Marketing Science Working paper series, William E. Simon School of Business, University of Rochester, Rochester.

Kihlstrom, R.E. and M.H. Riordan, 1984, "Advertising as a Signal," Journal of Political Economy, 92, 427-450.

Kohlberg, E. and J.-F. Mertens, 1986, "On the Strategic Stability of Equilibria," Econometrica, 54, 1003-1038.

Matthews, S.A. and D. Fertig, 1990, "Advertising Signals of Product Quality," CMSEMS discussion paper n. 881, Northwestern University, Evanston.

Meurer, M.J. and D.O. Stahl, 1994, "Informative Advertising and Product Match," International Journal of Industrial Organization, 12, 1-19.

Milgrom, P. and J. Roberts, 1986, "Price and Advertising Signals of Product Quality," Journal of Political Economy, 94, 796-821. 
Moorthy, S. and K. Srinivasan, 1995, "Signaling Quality with a Money-Back Guarantee: The Role of Transaction Costs," Marketing Science, 14, 442-466.

Muehling, D., J. Stoltman, and S. Grossbart, 1990, “The Impact of Comparative Advertising on Levels of Message Involvement," Journal of Advertising, 19, 41-50.

Nelson, P., 1974, "Advertising as Information," Journal of Political Economy, 84, 729-754.

Pechmann, C. and D.W. Stewart, 1990, "The Effect of Comparative Advertising on Attention, Memory, and Purchase Intentions," Journal of Consumer Research, 17, 180191.

— and S. Ratneshwar, 1991, “The Use of Comparative Advertising for Brand Positioning: Association versus Differentiation," Journal of Consumer Research, 18, 145-160.

Shieh, S., 1996, "Price and Money-Back Guarantees as Signals of Product Quality," Journal of Economics and Management Strategy, 5, 361-377.

Shimp, T., 1990, Promotion Management and Marketing Communications, 2nd edition. Chicago: The Dryden Press.

— and D. Dyer, 1978, "The Effects of Comparative Advertising Mediated by Market Position of Sponsoring Brand," Journal of Advertising, 7, 13-19.

Shy, O., 1992, "A Welfare Evaluation of Comparison Advertising," Tel Aviv Foerder Institute for Economic Research working paper 10/92.

— 1995, Industrial Organization: Theory and Applications, Cambridge, MA: The MIT Press. 